\title{
ANALISIS PENERAPAN PEMBELAJARAN MATEMATIKA BERBASIS PMRI PADA SEKOLAH DASAR DI KOTA BANDUNG
}

\author{
${ }^{1)}$ Nelly Fitriani, ${ }^{2)}$ Anik Yuliani \\ ${ }^{1)}$ Nhe.fitriani@gmail.com, ${ }^{2)}$ Anik.yuliani070886@yahoo.com \\ ${ }^{1,2)}$ Program Studi Pendidikan Matematika, STKIP Siliwangi
}

\begin{abstract}
ABSTRAK
PMR merupakan sebuah proyek pendidikan matematika di Belanda yang dimulai pada tahun 1970, saat itu Sekolah Dasar di Belanda terfokus kepada kemampuan Berhitung. Berhitung itu bersifat mekanistik, tidak memiliki matematisasi horizontal maupun matematisasi vertikal. Sedangkan PMR memiliki keduaduanya atau bersifat realistik. Tujuan penelitian ini adalah untuk menelaah apakah pembelajaran PMRI yang diterapkan di SD Percontohan sudah sesuai dengan karakteristik PMRI. Metode penelitian yang digunakan adalah deskriptif kualitatif, dengan populasi seluruh SD/MI di kota bandung dan sampelnya diambil 3 sekolah percontohan yang telah menerapkan PMRI selama 10 tahun pada level kelas V. Instrumen yang digunakan yaitu berupa Lembar Observasi. Kesimpulan yang diperoleh pada penelitian ini yaitu bahwa pembelajaran PMRI yang diterapkan di SD Percontohan sudah sesuai dengan karakteristik PMRI.
\end{abstract}

Kata kunci: Pembelajaran Matematika Realistik Indonesia

\section{A. PENDAHULUAN}

Pada saat ini ilmu pengetahuan telah berkembang sangat pesat, perkembangan ilmu pengetahuan tersebut memberikan peranan yang sangat besar dalam peningkatan kesejahteraan umat manusia. Perkembangan yang terjadi merupakan upaya untuk mengatasi kebutuhan masyarakat akan pendidikan dan pengajaran ilmu pengetahuan, dimana hal tersebut memberikan bekal kepada siswa agar dapat menyesuaikan diri dalam kehidupan masyarakat yang semakin terikat pada kemajuan ilmu pengetahuan.

PMR merupakan sebuah proyek pendidikan matematika di Belanda yang dimulai pada tahun 1970, saat itu Sekolah Dasar di Belanda terfokus kepada kemampuan Berhitung. Tokoh-tokoh PMR Belanda mengganti "Berhitung" dengan PMR karena menurut mereka "Berhitung" itu bersifat mekanistik, tidak memiliki matematisasi horizontal maupun matematisasi vertikal. Sedangkan PMR memiliki kedua-duanya atau bersifat realistik.

Treffers (1991:32) menggambarkan kepemilikan dan ketidakpemilikian dari model-model pembelajaran/ pendidikan matematika sebagai berikut,

\begin{tabular}{ccc} 
& \multicolumn{2}{c}{ Tabel 1 } \\
\hline \multirow{2}{*}{ Pengajaran } & \multicolumn{2}{c}{ Matematisasi } \\
\cline { 2 - 3 } & Horizontal & Vertikal \\
Mekanistik & - & - \\
Empiris & + & - \\
Strukturalis & - & + \\
Realistik & + & + \\
\hline
\end{tabular}

Catatan: - artinya tidak ada; + artinya ada

Dari bagan di atas terlihat bahwa pengajaran secara mekanistik itu tidak memiliki kedua-dua matematisasi sedangkan yang realistik memiliki kedua-duanya, yang empiris tidak memiliki matematisasi vertikal dan strukturalis tidak memiliki matematisasi horizontal. Tetapi Pembelajaran strukturalis seperti matematika modern itu bukan tidak memiliki matematisasi horizontal tetapi kepemilikannya sedikit. 
Sedangkan dalam yang realistik keterlibatannya banyak.

Pada suatu pertemuan (antara Pemerintah, Tim PMR Belanda, dan Tim PMRI), Tim PMR Belanda minta agar sekolah-sekolah tempat uji coba terdiri dari SD dan MI, maka dimulailah uji coba PMRI itu dibeberapa Sekolah Dasar dan Madrasah Ibtidaiyah dengan pusatpusatnya di UPI, USD, UNY, dan UNESA. Masing-masing pusat itu diminta untuk memilih 2 buah SD dan sebuah MIN/MI. Bandung memilih SDPN Setiabudi, SDPN Sabang, dan MIN Cicendo, maka selanjutnya terbentuklah SD dan MIN mitra UPI dimana sekolah tersebut menjadi sekolah percontohan untuk PMRI.

Setelah terbentuknya sekolah percontohan, dalam kurun waktu 10 tahun (sekitar tahun 2000-2010) banyak SD dan MI/MIN lain yang pembelajaran matematikanya menggunakan PMRI. SD, MI/MIN yang baru menggunakan PMRI (yang baru berminat untuk menerapkan PMRI) melakukan hal yang serupa dengan guru SD/MIN/MI, guru SL, dosen, dan yang terkait lainnya mengikuti workshop-workshop yang berkaitan dengan PMRI. Sehingga yang tadinya pusatnya hanya di UPI, USD, UNY, dan UNESA, sekarang hampir di setiap propinsi ada.

Setelah beberapa orang dosen STKIP Siliwangi Bandung diberikan kesempatan mengikuti sebuah workshop PMRI, STKIP Siliwangi berminat untuk mengembangkan dan menyebarkannya. Agar keinginan itu dapat terwujud, maka dibentuklah Tim PMRI di STKIP Siliwangi yang mana Tim tersebut harus mengetahui kondisi PMRI saat ini, minimum di Wilayah Bandung. Untuk menganalisis penerapan PMRI di Wilayah Bandung, penelitian yang akan dilakukan merupakan penelitian payung. Disini peneliti berniat untuk menganalisis sejauh mana penerapan PMRI di wilayah bandung, maka dari itu peneliti tertarik melakukan penelitian dengan judul "Analisis Penerapan Pembelajaran Matematika Berbasis PMRI pada Sekolah Dasar di Kota Bandung".

\section{B. KAJIAN TEORI DAN METODE}

PMRI atau RME merupakan suatu teori pembelajaran yang telah dikembangkan khusus untuk matematika. Konsep dari matematika realistik ini sejalan dengan kebutuhan untuk memperbaiki pendidikan matematika di Indonesia yang didominasi oleh persoalan bagaimana meningkatkan pemahaman siswa tentang matematika dan mengembangkan daya nalar dari siswa. RME pertama kali dikembangkan oleh Freudenthal pada tahun 1977 di Belanda.

Keberhasilan RME sebagai salah satu pendekatan dalam pembelajaran matematika di Belanda, memberikan pengaruh yang cukup besar dalam mempengaruhi program pembelajaran matematika di beberapa negara. Banyak Negara-negara yang tertarik untuk mengkajinya sehingga menjadikan PMRI sebagai alternatif dalam pembelajaran. Melalui PMRI, matematika diharapkan dekat dengan kehidupan sehari-hari siswa, dimana realistis dimaknai sebagai konteks yang berhubungan dengan pengalaman siswa maupun sesuatu yang tampak nyata dalam pikiran siswa (Fosnot, Dolk, Zolkower, Hersch, \& Seignoret, 2006; Van den Heuvel-Panhuizen, 2003).

\section{Prinsip-Prinsip PMRI}

Gravermeijer mengemukakan bahwa terdapat tiga prinsip kunci dalam pembelajaran PMR yakni:

\section{a. Petunjuk menemukan kembali/matematisasi progresif (guided reinvention/progressive mathematizing).}

Topik-topik disajikan, dengan memberikan kesempatan kepada siswa untuk mengalami proses yang sama sebagaimana konsep-konsep matematika ditemukan. Konsep-konsep siswa digali dengan cara memberikan masalah kontekstual yang mempunyai berbagai kemungkinan solusi, dilanjutkan dengan matematisasi. Proses belajar diatur sedemikian rupa sehingga siswa menemukan sendiri konsep atau hasil (Fauzan, 2001:2).

Treffers (Saragih, 2007: 14), mengemukakan bahwa bermatematika secara progresif terdiri dari dua komponen yaitu bermatematika secara secara horizontal dan vertikal. Contoh matematisasi horizontal adalah pengidentifikasian, perumusan dan pemvisualisasian masalah dalam cara yang 
berbeda, dan pentransformasian masalah dunia nyata ke masalah matematik. Contoh matematisasi vertikal adalah representasi hubungan-hubungan dalam rumus, perbaikan dan penyesuaian model matematik, penggunaan model-model yang berbeda, dan generalisasi (Panhuizen dalam Zainurie, 2007).

Pada proses matematisasi masalah-masalah realistik, siswa bermatematisasi horizontal ketika siswa mengidentifikasi bahwa soal-soal realistik harus ditransfer ke dalam soal bentuk matematika untuk lebih dipahami melalui penskemaan, perumusan, dan pemvisualisasian. Sedangkan dalam bermatematisasi vertikal siswa menyelesaikan bentuk matematika dari masalah realistik menggunakan konsep, operasi, dan prosedur matematika yang berlaku (Saragih, 2007 : $15)$.

\section{b. Fenomena yang bersifat mendidik (didactical phenomenology).}

Topik-topik matematika disajikan kepada siswa dengan mempertimbangkan dua aspek yaitu kecocokan aplikasi masalah kontekstual dalam pembelajaran dan kontribusinya dalam proses penemuan kembali bentuk dan model matematika dari soal kontekstual tersebut. Banyak fenomena yang dapat dikaitkan dengan konsep matematika tetapi tidak mungkin semuanya diberikan kepada siswa. Oleh sebab itu, guru sebagai perancang materi harus dapat memilih fenomena yang tepat dijadikan sebagai titik awal (starting point) pembelajaran (Gravemeijer dalam Saragih, 2011:58). Kedua pendapat ini menunjukan bahwa didactical phenomenology terkait dengan perencanaan masalah (materi kontekstual) yang tepat diberikan kepada siswa sebagai starting point pembelajaran. Sehubungan dengan itu sebelum menyajikan masalah kontekstual kepada siswa, guru perlu mengajukan pertanyaan tentang pantas atau tidaknya suatu masalah kontekstual tersebut dijadikan sebagai titik awal pembelajaran menuju matematika lebih lanjut dan mengantisipasi kemungkinan jawabanjawaban siswa.

Sehubungan dengan hal di atas, agar perencanaan pembelajaran khususnya yang berkaitan dengan didactical phenomenology guru harus mampu :

i. Menjadi perencana (planner) dan perancang (disigner) proses pembelajaran yang akan dilaksanakannya.

Penting bagi guru untuk mengetahui bagaimana seorang kontruktivis mengembangkan dan menemukan pengetahuannya. Guru dapat membuat perencanaan proses belajar sedemikian rupa yang di dalamnya terdapat rancangan pemberian pengalaman belajar yang tepat kepada siswanya agar mereka mencapai apa yang diharapkan oleh guru. Agar rencana dan rancangan belajarnya terlaksana dengan baik dan tepat, guru harus mampu memprediksi apa yang akan terjadi ketika rencana dan rancangan belajarnya itu diterapkan (on the table experiment). Dugaan atau prediksi tersebut dapat berupa; tingkah laku anak yang mungkin timbul, waktu yang diperlukan untuk menyelesaikan kegiatan, alternatif temuan yang akan diperoleh, kesulitan-kesulitan yang akan dihadapi anak ketika masalah disajikan bahkan hingga cara mengevaluasinya (Gravemeijer dalam Saragih, 2011:59).

c) Mengembangkan model sendiri (Self developed models)

Dalam menyelesaikan masalah kontekstual siswa diberi kesempatan untuk mengembangkan model mereka sendiri, sehingga dimungkinkan muncul berbagai model buatan siswa. Model-model tersebut diharapkan akan berubah dan mengarah kepada bentuk yang lebih baik menuju arah pengetahuan matematika formal, sehingga diharapkan terjadi urutan pembelajaran seperti berikut "masalah kontekstual" $\rightarrow$ "model dari masalah kontekstual tersebut" $\rightarrow$ "model kearah formal" $\rightarrow$ "pengetahuan formal". Guru dapat membuat perencanaan proses belajar sedemikian rupa yang di dalamnya terdapat rancangan pemberian pengalaman belajar yang tepat kepada siswanya agar mereka mencapai apa yang diharapkan oleh guru. Agar rencana dan rancangan belajarnya terlaksana dengan baik dan tepat, guru harus mampu memprediksi apa 
yang akan terjadi ketika rencana dan rancangan belajarnya itu diterapkan (on the table experiment). Dugaan atau prediksi tersebut dapat berupa; tingkah laku anak yang mungkin timbul, waktu yang diperlukan untuk menyelesaikan kegiatan, alternatif temuan yang akan diperoleh, kesulitan-kesulitan yang akan dihadapi anak ketika masalah disajikan bahkan hingga cara mengevaluasinya (Gravemeijer dalam Saragih, 2011:59).

Kesemua ini merupakan upaya dalam rangka learning trajectory terhadap bagaiamana siswa berpikir dalam mengembangkan dan menerima sebuah konsep matematika. Learning trajectory ini adalah untuk menggambarkan transformasi belajar yang dihasilkan dari partisipasi dalam aktivitas belajar matematika, atau learning trajectory juga diartikan serangkaian pembelajaran atau suatu lintasan belajar. Sudah barang tentu, guru juga harus bersiap terhadap beragam kemungkinan jawaban/respon yang tidak dapat diprediksinya, atau jawaban tersebut di luar jangkauan guru karena sangat mungkin muncul dari siswa dalam proses pembelajaran.

\section{Karakteristik PMRI}

Lima karakteristik yang dimiliki oleh PMRI (Saragih, 2007), yaitu:

a). The use of context (menggunakan masalah situasi nyata)

Menggunakan masalah situasi nyata/kontekstual, dalam pendekatan matematika realistik dijadikan sebagai titik awal siswa dalam belajar, untuk menopang terlaksananya suatu proses penemuan kembali (re-inventiont) sehingga secara formal siswa dapat memahami konsep matematika. Sehubungan dengan itu masalah kontekstual yang diajukan kepada siswa haruslah nyata dan benar-benar dikenal siswa dengan baik. Gravemeijer \& Doorman (Sabandar dalam Saragih, 2011: 63) memberi batasan bahwa masalah kontekstual adalah soal-soal yang menghadirkan kondisi atau lingkungan yang realistik bagi siswa. Dunia nyata adalah segala sesuatu di luar matematika, seperti mata pelajaran lain selain matematika, atau kehidupan sehari-hari dan lingkungan sekitar kita.

Menurut Panhuizen (2003: 9) masalah realistik yang dihadapkan kepada siswa tidak harus selalu dunia nyata, namun dapat berupa masalah dunia formal matematika yang dapat dibayangkan melalui media pembelajaran atau model. Bron (dalam Saragih, 2011:64) menyatakan bahwa konteks tidak harus selalu berupa situasi nyata dalam kehidupan seharihari, tetapi dapat pula berupa situasi fantasi. Figuiredo (dalam Haji, 2005) menjelaskan ciriciri konteks dalam RME adalah (a) dapat dibayangkan dengan mudah, dapat dikenal dan situasinya menarik, (b) berhubungan dengan dunia siswa, (c) tidak terpisah dari proses pemecahan soal, dan (d) dimulai dengan pengetahuan informal siswa dan terorganisasi secara matematis. Berdasarkan pendapatpendapat tersebut maka dapat disimpulkan bahwa masalah kontekstual bukan semata-mata berupa barang konkret, tetapi dapat berupa masalah formal (kehidupan sehari-hari) yang dapat dibayangkan dengan jelas dan tegas oleh siswa. Dalam praktek di kelas, masalah kontekstual yang diajukan guru senantiasa sesuai dengan pengalaman belajar siswa, mudah dibayangkan, sesuai dengan kesiapan siswa, dekat dengan kehidupan nyata, dan dapat dijadikan sebagai penghubung antara topik matematika yang dipelajari dengan pengalaman siswa. Dengan pengajuan masalah kontekstual yang demikian, siswa diharapkan dapat terbatu dalam memahami materi yang dipelajari dan memotivasi siswa karena mereka memahami manfaat atau kegunaan matematika serta memberi kesempatan kepada siswa untuk mengembangkan pemahamannya terhadap matematika berdasarkan pengetahuan yang telah dimilikinya.

Sehubungan dengan itu, maka pemilihan masalah kontekstual untuk diajukan kepada siswa harus melihat latar belakang peserta didik. Hal ini mengingat, dapat saja suatu topik bagi sekelompok siswa merupakan hal yang realistik namun bagi kelompok siswa yang lain bukan masalah yang realistik. 
b). The use of models (menggunakan modelmodel)

Proses pemodelan adalah salah satu karakteristik utama RME, yang bertujuan untuk menjembatani siswa memahami konsep formal matematik dari konsep informal yang dibuat siswa. Masalah kontekstual yang dihadapkan kepada siswa, agar dapat diselesaikan secara matematika maka permasalahan tersebut harus terlebih dahulu dinyatakan dalam bentuk model matematika. Hal inilah yang disebut dengan pemodelan. Kemampuan pemodelan ini sangat penting, karena berfungsi sebagai jembatan yang menghubungkan antara masalah kontekstual, matematika informal (matematisasi horizontal) dan matematika formal (matematisasi vertikal). Hal ini sesuai dengan pendapat Gravemeijer (dalam Saragih, 2011:66) bahwa pemodelan merupakan jembatan untuk mengubah masalah kontekstual menjadi bentuk formal.

\section{c). Student contributions (kontribusi siswa)}

Dalam proses pembelajaran dengan pendekatan RME akan terlihat pada saat siswa mengembangkan cara-cara menyelesaikan masalah yang diberikan menurut cara-cara mereka sendiri. Sehubungan dengan itu, maka siswa baik secara individual atau berkelompok harus memberikan kontribusinya dengan strategi-strategi penyelesaian yang dikembangkan sendiri oleh siswa dalam penyelesaian masalah tersebut. Strategi-strategi yang dikembangkan siswa dapat bersifat informal seperti skema, grafik, manipulasi aljabar, serta prosedur pemecahan masalah kontekstual sebagai sumber inspirasi dalam mengkonstruksi pengetahuan matematika formal dan diharapkan dapat berkembang ke arah yang positif.

\section{d). Interactivity (interaktivitas)}

Menggunakan interaktivitas, dalam mengembangkan penyelesaian-penyelesaian masalah kontekstual tidak dapat dihindari karena kemampuan siswa yang heterogen dan merupakan bagian penting dalam pendekatan ini. Siswa saling berinteraksi dan memberikan kontribusinya yang terwujud dalam bentuk negosiasi secara eksplisit, intervensi kooperatif, penjelasan, pembenaran, setuju, tidak setuju, pertanyaan atau refleksi dan evaluasi sesama siswa dan guru.

Interaksi-interaksi ini diharapkan dapat meningkatkan peran aktif siswa dalam pembelajaran sehingga meningkatkan keterampilan personal siswa dalam berdiskusi. Agar interaksi yang dibangun siswa tersebut optimal, guru harus dapat memilih dan menerapkan metode pembelajaran yang tepat. Salah satu metode untuk itu adalah belajar dalam kelompok. Namun perlu diingat bahwa, agar penyelesaian masalah yang dibuat siswa benar berdasarkan struktur matematika, interaksi antar siswa dengan siswa dan sebaliknya dengan guru tetap di bawah bimbingan guru.

\section{e). Intertwining (keterkaitan)}

Menggunakan keterkaitan dalam pendekatan RME ini bertujuan untuk memantapkan pengetahuan informal siswa dan sebagai alat untuk menggiring siswa menemukan matematika formal. Disamping itu, dengan keterkaitan ini siswa akan melihat adanya jalinan atau keterkaitan antar satu konsep dengan konsep lain atau satu materi dengan materi lain baik dalam matematika itu sendiri maupin dengan yang lain. Keterkaitan tersebut memperhatikan bahwa matematika bukanlah suatu pengetahuan yang bercerai berai, melainkan merupakan suatu ilmu pengetahuan yang utuh dan terpadu. Hal ini dimaksudkan aga proses pemahaman siswa terhadap konsep dapat dilakukan secara bermakna.

Tujuan dalam penelitian adalah untuk mengetahui sejauh mana penerapan PMRI di wilayah Bandung. Analisis terhadap penerapan PMRI di Sekolah Dasar Percontohan akan diuraikan secara deskriptif kualitiatif. Penelitian kualitatif deskriptif adalah penelitian yang menekankan pada keadaan yang seadanya dan berusaha mengungkapkan fenomena-fenomena yang ada dalam keadaan tersebut.

\section{PEMBAHASAN}

Berdasarkan hasil observasi terhadap pembelajaran yang dilakukan guru pada ketiga sekolah, yaitu guru matematika di SD Percobaan Negeri Sabang, 
SD Percobaan Negeri Setiabudi dan MIN Cicendo, diperoleh kesimpulan yang menjawab rumusan permasalahan dalam penelitian ini. Kesimpulan dari hasil observasi pembelajaran yang dilakukan oleh guru dengan menggunakan PMRI akan diolah secara deskriptif kualitatif. Dalam penelitian ini akan dilakukan analisis terhadap kesesuaian antara pembelajaran PMRI yang diterapkan di SD Percontohan dengan karakteristik PMRI yang sesungguhnya.

\section{A. Deskripsi pelaksanaan penelitian}

Penelitian ini dilaksanakan di 3 Sekolah yang terdapat di Kota Bandung yang telah menerapkan PMRI sejak 10 tahun terakhir. Ketiga sekolah tersebut yaitu SD MIN Cicendo, SD PN Setiabudi, dan SD PN Sabang, sekolah-sekolah tersebut merupakan sekolah percontohan yang terus dipantau oleh Institut pemgembangan PMRI. Kelas yang penulis gunakan dalam penelitian ini adalah kelas V. Untuk memperoleh jawaban atas tujuan penelitian tersebut maka dilakukan observasi terhadap ketiga sekolah. Observasi dilakukan oleh masing-masing 2 observer dari tiap sekolah, observer pertama adalah guru dari masing-masing sekolah yang diteliti dan observer kedua adalah peneliti sendiri.

Penelitian dilaksanakan sejak tanggal 3 November 2014 hingga 21 November 2014. Adapun agenda kegiatan penelitian tersaji dalam tabel berikut:

Tabel 2

\section{Kegiatan selama penelitian}

\begin{tabular}{|l|l|}
\hline Hari, Tanggal & Kegiatan \\
\hline $\begin{array}{l}\text { Senin, 3 November } \\
2014\end{array}$ & $\begin{array}{l}\text { Observasi Pembelajaran PMRI di SD } \\
\text { PN Sabang }\end{array}$ \\
\hline $\begin{array}{l}\text { Selasa, 18 November } \\
2014\end{array}$ & $\begin{array}{l}\text { Observasi Pembelajaran PMRI di SD } \\
\text { PN Setiabudi }\end{array}$ \\
\hline Jumat, 21 November & Observasi Pembelajaran PMRI di \\
\hline
\end{tabular}

\section{B. Analisis Data Penelitian}

Berdasarkan hasil observasi yang dilakukan pada 3 Sekolah diperoleh data mengenai karakteristik PMRI yang dilaksanakan di sekolah-sekolah tersebut. Rekapitulasi persentase karakteristik pembelajaran PMRI berdasarkan hasil observasi dapat dilihat pada tabel 3 di bawah ini.

Tabel 3

Rekapitulasi Persentase Hasil Observasi

\begin{tabular}{|c|c|c|c|c|c|c|c|}
\hline \multirow{2}{*}{ No } & \multicolumn{2}{|c|}{$\begin{array}{c}\text { MIN } \\
\text { CICENDO }\end{array}$} & \multicolumn{2}{|c|}{$\begin{array}{c}\text { SD PN } \\
\text { SABANG }\end{array}$} & \multicolumn{2}{|c|}{$\begin{array}{c}\text { SD } \\
\text { SETIABUDI }\end{array}$} & \multirow{2}{*}{$\%$} \\
\hline & 01 & $\mathbf{0 2}$ & O1 & O2 & 01 & $\overline{02}$ & \\
\hline 1 & 2 & 3 & 3 & 2 & 3 & 3 & 88,89 \\
\hline 2 & 3 & 3 & 3 & 2 & 3 & 3 & 94,44 \\
\hline 3 & 0 & 2 & 3 & 2 & 3 & 3 & 72,22 \\
\hline 4 & 2 & 3 & 2 & 3 & 2 & 2 & 77,78 \\
\hline 5 & 2 & 3 & 3 & 3 & 3 & 3 & 94,44 \\
\hline 6 & 3 & 3 & 3 & 2 & 3 & 2 & 88,89 \\
\hline 7 & 3 & 3 & 3 & 3 & 3 & 3 & 100,00 \\
\hline 8 & 3 & 3 & 3 & 3 & 3 & 3 & 100,00 \\
\hline 9 & 3 & 2 & 2 & 3 & 2 & 3 & 83,33 \\
\hline 10 & 3 & 3 & 3 & 2 & 3 & 3 & 94,44 \\
\hline 11 & 3 & 3 & 3 & 3 & 3 & 3 & 100,00 \\
\hline 12 & 3 & 3 & 3 & 2 & 3 & 3 & 94,44 \\
\hline 13 & 3 & 3 & 3 & 3 & 3 & 3 & 100,00 \\
\hline 14 & 3 & 3 & 3 & 3 & 3 & 3 & 100,00 \\
\hline
\end{tabular}

Berdasarkan analisis secara keseluruhan dari hasil observasi ketiga sekolah yang telah menerapkan pembelajaran berbasis PMRI, dapat disimpulkan bahwa pembelajaran PMRI yang diterapkan sudah sesuai dengan karakteristik dari PMRI itu sendiri, 
misalnya sudah menggunakan masalah kontekstual karena menurut Gravemeijer (Ahli PMRI), dalam PMRI, menggunakan masalah situasi nyata/kontekstual dijadikan sebagai titik awal siswa dalam belajar untuk menopang terlaksananya suatu proses penemuan kembali (re-inventiont) sehingga secara formal siswa dapat memahami konsep matematika. Masalah kontekstual yang diajukan kepada siswa haruslah nyata dan benarbenar dikenal siswa dengan baik.

Selanjutnya realistik, menurut Panhuizen (Ahli PMRI), melalui PMRI, matematika diharapkan dekat dengan kehidupan sehari-hari siswa, dimana realistik dimaknai sebagai konteks yang berhubungan dengan pengalaman siswa maupun sesuatu yang tampak nyata dalam pikiran siswa. Pada masalah-masalah realistik, siswa bermatematisasi horizontal (ketika siswa mengidentifikasi bahwa soal-soal realistik harus ditransfer ke dalam soal bentuk matematika untuk lebih dipahami melalui penskemaan, perumusan, dan pemvisualisasian), yang selanjutnya harus dilanjutkan kepada matematisasi vertikal untuk menyelesaikan bentuk matematika dari masalah realistik yang diberikan, sehingga terjadi penguatan konsep yang baik dan tahan lama.

Pembelajarannya bersifat konstruktivisme, dan mengarahkan siswa untuk menemukan konsep, siswa berpartisipasi aktif dalam pembelajaran, guru membuat bahan ajar (RPP dan LKS) bersumber dari buku PMRI, dan pada akhir pembelajaran guru mengadakan refleksi kegiatan. Terlihat dari beberapa buah gambar berikut ini.

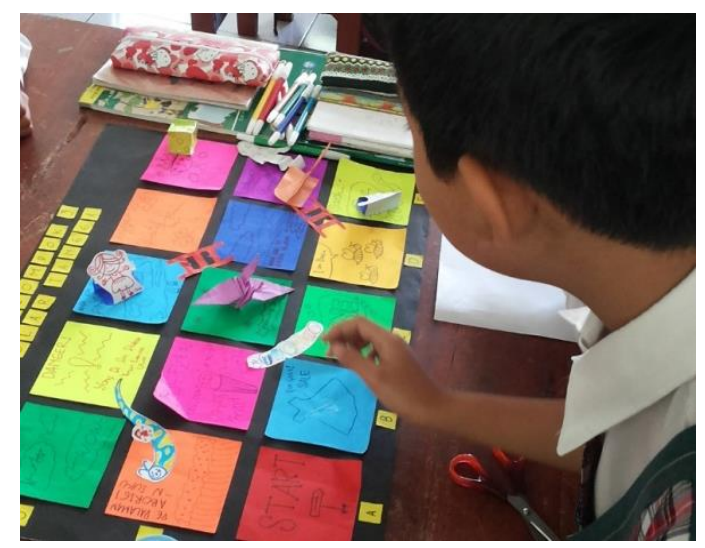

Gambar 1

Media Pembelajaran yang Bersifat Kontekstual di SD PN Setiabudi

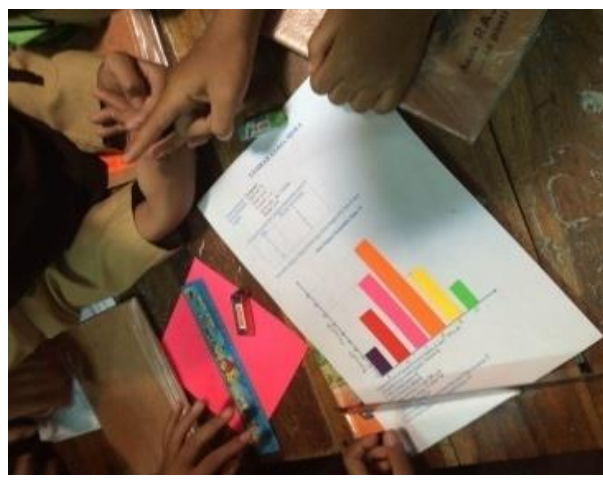

Gambar 2

Siswa menemukan Konsep melalui Konstruksi dari konsep Konkret ke Abstrak

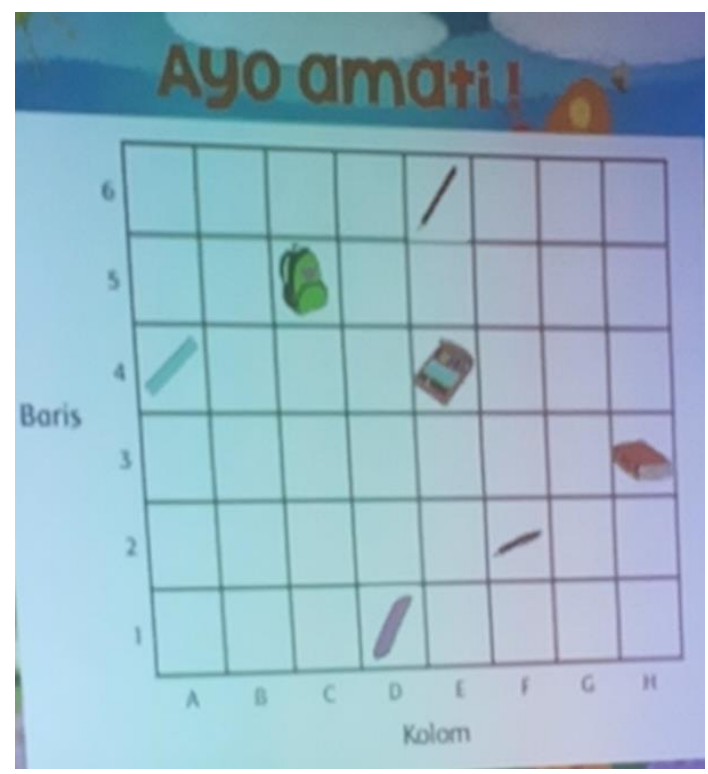

Gambar 3

Contoh Gambar LKS Letak Koordinat

Guru-guru pada ketiga sekolah tersebut sudah menerapkan PMRI selama kurang lebih 10 tahun, sehingga mereka sudah terbiasa dengan pembelajaran ini, dan melalui pembelajaran ini guru-guru sangat terbuka dengan adanya pembaharuan Kurikulum terbaru yaitu Kurikulum 2013, karena pada dasarnya PMRI sangat sejalan dengan Kurikulum 2013. 


\section{KESIMPULAN}

Beradasarkan analisis secara keseluruhan dari hasil observasi ketiga sekolah yang telah menerapkan pembelajaran berbasis PMRI, dapat disimpulkan bahwa pembelajaran PMRI yang diterapkan sudah sesuai dengan karakteristik dari PMRI itu sendiri.

Berdasarkan penelitian yang dilakukan, maka saran yang dapat disampaikan yaitu :

1. Diharapkan agar IP-PMRI dapat terus membina dan mengembangkan PMRI di sekolahsekolah percontohan berupa pengembangan bahan ajar, alat peraga dan workshop-workshop bagi guru, dengan demikian guru-guru akan terus termotivasi untuk menerapkan PMRI disetiap pembelajaran matematika.

2. Sekolah Percontohan diharapkan melakukan sosialisasi ke sekolah-sekolah lain guna memperkenalkan PMRI, dengan demikian diharapkan sekolah-sekolah (minimal di Bandung) mengenal dan menerapkan PMRI.

\section{DAFTAR PUSTAKA}

Fosnot, C. T., Dolk, M., Zolkower, B., Hersch, S., \& Seignoret, H. (2006). Mathematics in the City: Measuring Teacher Change in Facilitating Mathematizing.

Fauzan, A. (2001). Applying Realistic Mathematics Education (RME) in Teaching Geometry in Indonesian Primary Schools. Thesis

http://zainurie.wordpress.com/2007/04/13/p embelajaran-matematika-realistik-rme/ [Juli 2011].
Megister, Den Haag: PrintPartners Ipskamp - Enschede

Saragih, S. (2007). Menumbuhkembangkan Berpikir Logis dan Sikap Positif terhadap Matematika melalui Pendekatan Matematika Realistik. [Online]. Tersedia: http://zainurie.files.wordpress.com/2007/11/j 61 091.pdf

[Juli 2011].

Saragih, S. (2011). Penerapan Pendekatan Pembelajaran Matematika Realistik dan Kelompok Kecil untuk Meningkatkan Kemampuan Keruangan, Berpikir Logis dan Sikap Positip terhadap Matematikasiswa Kelas VIII. Disertasi. UPI Bandung: tidak diterbitkan.

Panhuizen, M. V. D. H. (2003). The Didactical Use Of Models In Realistic Mathematics Education: An Example From A Longitudinal Trajectory On Percentage. Educational Studies in Mathematics 54: 9-35, 2003.

Zainurie. (2007). Pembelajaran Matematika Realistik (RME). [Online]. Tersedia: 